\title{
Individual differences in imagination inflation
}

\author{
CHRISTOPHER HEAPS and MICHAEL NASH \\ University of Tennessee, Knoxville, Tennessee
}

\begin{abstract}
Garry, Manning, Loftus, and Sherman (1996) found that when adult subjects imagined childhood events, these events were subsequently judged as more likely to have occurred than were not-imagined events. The authors termed this effect imagination inflation. We replicated the effect, using a novel set of Life Events Inventory events. Further, we tested whether the effect is related to four subject characteristics possibly associated with false memory creation. The extent to which subjects inflated judged likelihood following imagined events was associated with indices of hypnotic suggestibility and dissociativity, but not with vividness of imagery or interrogative suggestibility. Results suggest that imagination plays a role in subsequent likelihood judgments regarding childhood events, and that some individuals are more likely than others to experience imagination inflation.
\end{abstract}

An important question in the recovered memory debate is when and how people come to falsely believe that events have occurred in their past. In a recently reported study, Garry, Manning, Loftus, and Sherman (1996) found that when adult subjects imagined childhood events, they were subsequently more likely to judge that these imagined events had occurred than they were to judge that nonimagined events had occurred. The authors termed this effect imagination inflation, and they urged caution in the use of procedures that involve imagination in recovered memory situations. Garry et al. discussed a number of possible explanations for the imagination inflation effect. Most notably, increases in subjective likelihood after repeated testing could represent hypermnesia, the increased recall of accurate information over successive tests. However, prior research on the effects of imagination on the judged likelihood of future events has demonstrated that the possible presence of a memory is not necessary for the production of such increases (Carroll, 1978; Gregory, Cialdini, \& Carpenter, 1982). That is, even when subjects imagine future events, increases in the judged likelihood of an event can be produced as a result of imagination. The possibility that such increases can occur with past events may bring to light one method by which individuals come to believe that an event has occurred even though they were previously either uncertain about its occurrence or certain that it had not occurred.

When imagining an event that has never actually happened, the imaginer must create a counterfactual causal scenario for the event in conjunction with the visualization (Wells \& Gavanski, 1989). This combination of perceptual, contextual, and semantic information may make the event more available in memory (Tversky \& Kahneman, 1973) and more easily confused with memorial rep-

We thank Grant Benham, Brian Burney, Lisa Hargreaves, and Norris Smith for their assistance in data collection. Correspondence concerning this article should be addressed to C. Heaps, Department of Psychology, University of Tennessee, 307 Austin Peay Bldg., Knoxville, TN 37996-0900 (e-mail: cheaps@utk.edu). resentations originating with external sources (i.e., perceived events; see Johnson, Hashtroudi, \& Lindsay, 1993). As a result, imagination can produce the belief that the event actually has occurred, complete with recollective experience (Hyman, Gilstrap, Decker, \& Wilkinson, 1998; Hyman \& Pentland, 1996). Importantly, the effect of imagination appears to increase as a function of the number of imaginings (Goff \& Roediger, 1998). If imagination inflation were indeed a characteristic of human recall, it would have a chilling effect on the confidence we can have about memories derived from investigative procedures involving requests to imagine. Accordingly, the effect itself needs to be replicated in other labs, under different conditions, with diverse samples, and, of course, with novel events. The initial aim of the present study is to address the question: How reliable and robust is the imagination inflation effect?

\section{Potential Predisposing Subject Characteristics}

Some debate has taken place about the idea that some individuals, more than others, may be likely to create false memories. In discussing her work on memory, Loftus (1997) commented that "We need to discover what types of individuals are particularly susceptible to these forms of suggestion and who is resistant" (p. 75). Thus, the present study poses a second question: If the imagination inflation effect is reproducible, are there cognitive or personality characteristics that might predispose some subjects to inflate more than others? Accordingly, we examined four characteristics of subjects that might plausibly account for individual differences in the extent of inflation.

Imagery vividness has been implicated in source monitoring errors (Dobson \& Markham, 1993; Markham \& Hynes, 1992). For example, Dobson and Markham found that subjects with high scores on Marks's (1973) Vividness of Visual Imagery Questionnaire (VVIQ) were more likely to make source monitoring errors for the events of a story than were subjects with low VVIQ scores. Labelle and Perry (1986) found that subjects' responses to hypnotically suggested false memories were predictable in part 
from their capacity for imagery. We suspected that vividness of imagery would be positively associated with the imagination inflation effect.

There is widespread popular belief and some professional support for the notion that individuals who are highly suggestible are prone to creating false memories. In light of suggestion techniques used by some therapists and law enforcement officials in several published cases, the possibility exists that individuals who are more suggestible are likely to report remembering experiences that they have not had (Kassin, 1997; Ofshe, 1992). We examined two types of suggestibility and their relation to imagination inflation.

Interrogative suggestibility refers to suggestibility in a situation in which a dialogue exists between one or more interrogators and a single respondent to arrive at an agreedupon version of "the facts." Through the use of leading questions containing postevent misinformation and the use of false feedback regarding subjects' answers, the Gudjonsson Suggestibility Scale (GSS; Gudjonsson, 1984) measures the degree to which individuals are susceptible to the influence of an authoritative questioning source. We examined whether interrogative suggestibility as measured by the GSS would be positively related to imagination inflation scores.

A second type of suggestibility that is conceptually and empirically distinct from interrogative suggestibility (Register \& Kihlstrom, 1988) is hypnotic suggestibility. Hypnosis is sometimes used as a technique for "recovering" lost memories (Driscoll \& Wright, 1991), and subjects with higher hypnotic suggestibility scores report more false memories (Barnier \& McConkey, 1992; Laurence \& Perry, 1983; Sheehan, Statham, \& Jamieson, 1991). We examined whether hypnotic suggestibility would be positively related to imagination inflation scores.

Dissociation is defined in different ways by theorists, depending on whether the focus of interest is pathology or normal variability in a cognitive process. What these definitions have in common is the notion that some individuals, more than others, fail to distinguish and integrate memories, fantasies, motivations, and actions in awareness (Spiegel, 1995; Whalen \& Nash, 1996). It is the broad continuum of dissociativity, its associated disruption in memory, and the propensity to confuse event with fantasy that defines the concept's relevance to imagination inflation. We expected to find a positive correlation between dissociativity and extent of imagination inflation.

\section{Study Rationale}

In the present study, subjects indicated the initial likelihood that a number of events had happened to them during their childhood. As per Garry et al.'s (1996) imagination inflation methodology, target events that were judged unlikely to have occurred were selected to be imagined 2 weeks later by some subjects and to serve as control items for other subjects. Following imagination, subjects provided a second likelihood rating for each event under the pretense that the initial responses had been lost. Although the procedure was identical to that reported by Garry et al., the list of events was different. We expected that increases in judged likelihood would be significantly greater for imagined events than for not-imagined events if the imagination inflation effect is reproducible across a different list of events. Further, we hypothesized that the magnitude of inflation would be associated with ability to imagine vividly, the degree of interrogative and hypnotic suggestibility, and the amount of reported disassociativity.

\section{METHOD}

\section{Subjects}

Fifty-five subjects ( 34 women and 21 men, mean age $=22.3$ years) participated for extra course credit. All were enrolled in an upper level psychology course at the University of Tennessee, Knoxville.

\section{Materials}

A 42-item Life Events Inventory (LEI) was adapted from Garry et al. (1996). The LEI asked subjects to judge how likely it was that each event had or had not happened to them before the age of 10 . Subjects rated the likelihood of occurrence for each event from 1 (definitely did not happen) to 8 (definitely did happen) by circling the appropriate number beneath each item. Eight target items were chosen on the basis of pretest descriptive statistics, with a preference for those events that were least likely to have occurred to the subjects in the study (see Table 1). Selection of the target items was also somewhat intuitive, with a preference for items not used in the Garry et al. study. Overall, seven of the eight target items used in this study were not used as target items by Garry et al. The one critical item common to both studies was "Broke a window with your hand."

Mental imagery ability was measured by the VVIQ (Marks, 1973), which has shown acceptable levels of internal consistency $(\alpha=$ $.91)$ and test-retest reliability $(r=.87$; Rossi, 1977).

The GSS (Gudjonsson, 1984) was administered in order to assess interrogative suggestibility. This scale consists of two separately administered parts. In Part 1, subjects listened to a narrative passage and provided a free recall account of the passage's content. Part 2 took place three days after Part 1. In Part 2, subjects provided a second free recall and then answered 20 cued recall questions, 15 of which contained misleading information. Regardless of their responses to the cued recall questions, subjects were told that their performance was poor and that the questions would have to be readministered. Subjects then provided a second cued recall. The Total Suggestibility score for each subject was calculated as the sum of (1) the number of times that a subject answered in accord with the erroneous conclusions of the leading questions during the first cued recall administration (known as yield), and (2) the number of times that a subject changed his/her answers from the first to the second cued recall administration as a result of the false feedback regarding his/her performance (known as shift).

The GSS has shown acceptable internal consistency $(\alpha=.88$ for yield, and $\alpha=.82$ for shift) and test-retest reliability (Gudjonsson, 1984), and scoring of the suggestibility measures has been shown to be highly reliable (Clare, Gudjonsson, Rutter, \& Cross, 1994).

The Waterloo-Stanford Scale of Hypnotic Susceptibility, Group C scale (WSGC, 11-point version; Bowers, 1993) was administered in order to assess hypnotic suggestibility. The scale consists of a series of 11 suggestions given after a hypnotic induction. For example, subjects are asked to extend their right hand and to feel a heavy weight pulling it downward. One point is given for each suggestion the subject passes, or responds to, and a subject's hypnotic suggest- 
Table 1

LEI Pretest and Change Information for Critical Items $(\boldsymbol{N}=\mathbf{5 5})$

\begin{tabular}{|c|c|c|c|c|}
\hline \multirow[b]{2}{*}{ Event } & \multicolumn{2}{|c|}{ Pretest Responses } & \multicolumn{2}{|c|}{$\begin{array}{l}\text { Percent of Subjects } \\
\text { With Positive Change }\end{array}$} \\
\hline & $M$ & $S D$ & Imagined & Not Imagined \\
\hline \multicolumn{5}{|l|}{ Set A } \\
\hline Saw your house burn down & 1.67 & 1.32 & 3.7 & 7.1 \\
\hline Broke a window with your hand & 1.69 & 1.69 & 11.1 & 21.4 \\
\hline Ran away from home & 2.89 & 2.67 & 29.6 & 21.4 \\
\hline $\begin{array}{l}\text { Went on hot air balloon ride } \\
\text { with classmates }\end{array}$ & 1.42 & 1.40 & 14.8 & 10.7 \\
\hline \multicolumn{5}{|l|}{ Set B } \\
\hline Shook hands with the President & 1.22 & 1.15 & 14.3 & 0.0 \\
\hline $\begin{array}{l}\text { Got caught sneaking out of } \\
\text { the house late at night }\end{array}$ & 1.67 & 1.65 & 42.9 & 37.0 \\
\hline Your house was robbed & 2.06 & 2.18 & 25.0 & 3.7 \\
\hline $\begin{array}{l}\text { Fell off your bicycle and } \\
\text { got stitches in your leg }\end{array}$ & 1.78 & 1.92 & 39.3 & 14.8 \\
\hline Overall & 1.80 & 1.75 & 22.6 & 14.5 \\
\hline
\end{tabular}

Note-Judgments were made on an 8-point scale ( 1 = definitely did not happen, $8=$ definitely did happen).

ibility score is taken as the sum of all passed items $(0-11)$. The WSGC has shown acceptable levels of internal consistency $(\alpha=.80$; Bowers, 1993), and it correlates highly with other forms of the WaterlooStanford.

The Dissociative Experiences Scale (DES; Bernstein \& Putnam, 1986) was administered to assess dissociativity. Form $C$ of the DES (Wright \& Loftus, in press) has been shown to be most appropriate for use with nonclinical populations, and it has shown high levels of internal consistency ( $\alpha=.93$; Wright $\&$ Loftus, in press)

\section{Procedure}

All subjects took part in four sessions. Some care was taken to prevent subjects from being aware that the sessions were part of a single study until debriefing following Session 4. Different experimenters were used during the sessions of the study. Also, subjects were falsely briefed regarding the purposes of each session and were led to believe that data were being collected for four separate studies.

Session 1. During regular class times, subjects took part in a group hypnotic induction administered by Experimenter 1 . The WSGC was administered. Subjects were told that their WSGC score would be used to demonstrate individual differences in the influence of hypnosis on cognition.

Session 2. At least 2 weeks later, groups of subjects were read the narrative passage from the GSS by Experimenter 2 and free recall was immediately taken (Part 1). Subjects then made individual appointments to complete Part 2 of the GSS in the laboratory of Experimenter 23 days later. Subjects were told that the GSS tested "memory ability."

Session 3. Upon arrival, subjects were greeted by Experimenter 2 and individually completed Part 2 of the GSS in the laboratory. Experimenter 2 then asked them to participate in two other studies by Experimenter 3 and Experimenter 4 . If they agreed, Experimenter 2 departed, and Experimenters 3 and 4 administered a packet consisting of the LEI (pretest), VVIQ, and DES. As with Garry et al. (1996), subjects were told that Experimenter 3 was "interested in how vividly and completely people could imagine events, and that they would complete the LEI [and VVIQ in the present case] to gather baseline data on how frequently these events actually occurred" (p. 210). However, events were not imagined until Session 4, 2 weeks later. Subjects were told that the DES was part of a scale validation effort for Experimenter 4.

Session 4. The procedure and instructions used in Session 4 were identical to those reported by Garry et al. (1996; Session 2), though the critical items were changed. Subjects made appointments to come to the laboratory of Experimenter 3 in groups of $1-5$ between 14 and 15 days after completing the LEI during Session 3. In Session 4 , the eight critical items were split into two sets of four. Subjects were randomly assigned to imagine the critical items in either Set A or Set B (see Table 1), with the items in the other set serving as controls.

As in Garry et al. (1996), subjects were seated in a semicircle in comfortable chairs around the experimenter and were given a clipboard holding a packet with a blank sheet on top. Subjects were instructed not to look at the packets yet. Subjects were then told that they would imagine four events and answer some questions about what they had imagined. Subjects were given instructions on how to complete the imagination effectively (i.e., closing eyes if desired, including familiar people and places, etc.), and then they imagined each of the four events in turn. The imagination of each event occurred in two steps. First, subjects were read a description of the general setting and initial details of the event. Approximately $1 \mathrm{~min}$ was allowed after reading the description for subjects to form a complete mental image, and then subjects were instructed to turn to the next page of the packet and answer the questions that they found there regarding their imagination of the event. Subjects were instructed to stop once they had answered the last question on the page, not to turn to further pages, and to look up when finished. Second, once the questions were answered, the description of the rest of the event was read. Subjects were again given some time to form a complete mental image, and they then again answered another set of questions about their imagination of the event.

This sequence was repeated for each of the four items. The experimenter then pretended to have misplaced the original questionnaires filled out by the subjects, left the room to "look" for another set for everyone, and upon return apologetically asked the subjects to fill out another version of each. Subjects were not given instruction regarding whether they should answer the questions as they had before. Subjects were then dismissed. This administration of the LEI served as the posttest.

\section{RESULTS}

Analysis of the pretest responses for critical items demonstrated that subjects overwhelmingly reported that these events probably had not happened to them (see Table 1) Overall, 90\% (397/440) of the pretest answers for target 
items fell between 1 and 4 . Thus, for each subject, seven of his/her eight responses to the critical items fell between 1 and 4 , with most of these $(88 \%$, or 351$)$ being given a rating of 1 , or definitely did not happen. Across all critical items, the mean number of subjects who initially reported that an item probably had not happened was 49.6, and the median was $50(91 \%)$. A similar pattern holds for each target item individually. Thus, the pretest data are heavily weighted by responses indicating very low likelihood.

The major question to be addressed is whether there exists a significantly greater amount of change in judged likelihood for items that were imagined over those that were not imagined, as reported by Garry et al. (1996). The percentage of positive change from pretest to posttest was calculated for each of the eight critical items according to whether the item was imagined or not imagined. These results are presented in Table 1. Across these items, the percentage of positive change for imagined items was $8.1 \%$ greater than the percentage of positive change for items that had not been imagined. A paired $t$ test treating items as cases revealed that this difference was significant $[t(7)=1.94, p<.047, S E=4.17$, one tailed]. The effect size was .68. Another way of testing the effect, not reported by Garry et al., is whether judged likelihood changes are greater for imagined events across subjects, rather than across events. Subjects' average increase for imagined events was $.44(S D=.89)$, whereas subjects' average increase for not-imagined events was . $18(S D=$ .60 ). A paired $t$ test treating subjects as cases revealed that this difference was also significant $[t(54)=-1.89, p<$ $.032, S E=0.14$, one tailed]. The effect size was .44 .

Subjects varied in the degree to which their judged likelihood changed after imagining the events. Change scores ranged from -7 to +14 , with many subjects $(24$, or $44 \%)$ reporting positive change, slightly fewer $(23$, or $42 \%)$ reporting no change, and a few ( 8 , or $15 \%)$ reporting negative change across the four imagined items. Note that these percentages add to $101 \%$ due to rounding. A standard multiple regression was performed between change scores for imagined items as the dependent variable and imagery vividness, interrogative suggestibility, hypnotic suggestibility, and dissociativity as independent variables. Examination of scatter plots, residual plots, and distance measures revealed no outliers and no violations of regression assumptions. Table 2 displays the correlations between the variables, the unstandardized regression coefficients $(B)$ and intercept, the standardized regression coefficients $(\beta)$, the semipartial correlations $\left(s r_{i}^{2}\right)$, and $R^{2}$, adjusted $R^{2}$. $R$ for regression was significantly different from zero $[F(4,50)=3.61, p<.01]$. For the two regression coefficients that differed significantly from zero, $95 \%$ confidence limits were calculated. The confidence limits for hypnotic suggestibility were .13 to 1.04 , and those for dissociativity were .17 to 1.54 . Only two of the independent variables contributed significantly to prediction of imagination inflation scores: hypnotic suggestibility $\left(s r_{i}^{2}=.32\right)$ and dissociativity $\left(s r_{i}^{2}=.31\right)$. Altogether, $22 \%$ ( $16 \%$ adjusted) of the variability in imagination inflation scores was predicted by knowing scores on the four independent variables. Univariate analysis revealed that only hypnotic suggestibility $(r=.35, p<.01)$ and dissociativity $(r=.34, p<.01)$ were related to inflation scores.

\section{DISCUSSION}

These findings confirm those of Garry et al. (1996) and further suggest that imagination plays a role in subsequent likelihood judgments regarding childhood events. The major difference between the present investigation of imagination inflation and the Garry et al. study lies in the use of a substantially different set of LEI target events. Thus, it appears that in situations in which individuals do not remember events from their personal past and are confident that such events have not occurred, the act of imagination can serve to raise the subjective likelihood of occurrence. Importantly, our results also suggest that the tendency to experience the imagination inflation effect is not related to one's suggestibility in interrogative situations or to the quality of one's mental images, but to

Table 2

Standard Multiple Regression of Imagery Vividness,

Interrogative Suggestibility, Hypnotic Suggestibility, and Dissociativity on Change Scores for Imagined Items $(N=\mathbf{5 5})$

\begin{tabular}{lcrrrrrrr}
\hline Variables & IMAG (DV) & \multicolumn{1}{c}{ IV } & \multicolumn{1}{c}{ IS } & HS & DIS & \multicolumn{1}{c}{$B$} & $\beta$ & \multicolumn{1}{c}{$s r^{2}$} \\
\hline IV & -.06 & & & & & -0.59 & -0.08 & -.08 \\
IS & -.05 & .27 & & & & 0.03 & 0.04 & .04 \\
HS & $.35^{*}$ & -.01 & -.20 & & & $0.59^{*}$ & 0.33 & .32 \\
DIS & $.34^{*}$ & .05 & -.01 & .08 & & $0.86^{*}$ & 0.32 & .31 \\
& & & \multicolumn{7}{c}{ Intercept $=-2.39$} \\
$M$ & 1.76 & 3.87 & 11.40 & 4.13 & 4.23 & & \\
SD & 3.55 & 0.48 & 4.57 & 2.00 & 1.30 & & & $R=.47^{*}$ \\
& & & & & & & $R^{2}=.22$ \\
& & & & & & Adjusted $R^{2}=.16$ \\
\hline
\end{tabular}

Note-IMAG, change scores for imagined items; IV, imagery vividness; IS, interrogative suggestibility; HS, hypnotic suggestibility; DIS, dissociativity. ${ }^{*} p<.01$. 
one's tendency to respond to hypnotic suggestion and the frequency of dissociative experiences in one's day-to-day cognition.

Our results concerning who inflated may provide clues into what factors are important, and which are not, for the creation of false beliefs about the past. Although the importance of social pressure to remember in many recovered memory situations cannot be discounted, the characterization of individuals who create false memories as "suggestible" may be unwarranted (Leavitt, 1997). The lack of relationship between interrogative suggestibility and imagination inflation may mean that memory creation is not the result of social compliance or reliance on authority to make decisions about the "truth" of memory. Instead, the relationship of hypnotic suggestibility and dissociativity to imagination inflation suggests that, under appropriate conditions, stable and intrinsic aspects of the way in which an individual processes information may make the creation of false beliefs more likely (Hyman \& Billings, in press).

Johnson has suggested that characteristics of the recollective experience are used in judging a remembered event's source (Johnson, Foley, Suengas, \& Raye, 1988). Specifically, imagined events that contain unusually large amounts of perceptual and contextual information and that require little effort to create are those which may be mistaken for perceived events by virtue of being uncharacteristic of internal memories. Although we did not measure the quality of imagery in the imagined events themselves, the general capacity to imagine vividly was not related to imagination inflation, suggesting that imagined events that are later inflated are not more vivid than those which were not inflated. However, the relationship between imagination inflation and hypnotizability supports the contention that imagined events that are later believed to originate with perceptual experience are those that require little effort for creation. Highly hypnotizable subjects often report experiencing imagined sensations as detached from volitional control and thereby experience them as originating outside the body (e.g., "I just found myself moving my hand without knowing it"; Bowers \& Farvolden, 1996; Hilgard, 1965; Kihlstrom, 1987). Although this type of experience is characteristic of dissociative subjects as well (Cardena, 1994), dissociativity and hypnotizability each independently predicted imagination inflation. Dissociative subjects experience frequent disruptions in episodic memory, often finding external evidence or confirmation of events that are not remembered. As suggested by Hyman and Billings (in press), such subjects may consequently adopt a lower criterion for accepting memories as real. Or, dissociative experiences may disrupt the encoding of cognitive operations associated with experience, making the creation of imagined events seem less effortful in retrospect.

On the basis of the present results, we propose that the creation of false beliefs about the past is due in part to stable, intrinsic aspects of an individual's cognition. If decisions about the source of memorial representations are based on the characteristics of recollective experience, the capacity to create a believable recollective experience is more likely for some subjects than others by virtue of a cognitive style that enables such constructions. However, how much variability in imagination inflation can be explained by individual difference factors is still unknown. Also, the question of how to characterize a style with a proclivity toward imagination inflation has yet to be answered fully. Nevertheless, a more detailed understanding of who is likely to mistake imagination for reality and under what conditions could lead to a more informed awareness about when and when not to be skeptical of claims about the past.

\section{REFERENCES}

Barnier, A. J., \& MCConkey, K. M. (1992). Reports of real and false memories: The relevance of hypnosis, hypnotizability, and test control. Journal of Abnormal Psychology, 101, 521-527.

Bernstein, E. M., \& Putnam, F. W. (1986). Development, reliability, and validity of a dissociation scale. Journal of Nervous \& Mental Disease, 174, 727-735.

Bowers, K. S. (1993). The Waterloo-Stanford Group C (WSGC) Scale of Hypnotic Susceptibility: Normative and comparative data. International Journal of Clinical \& Experimental Hypnosis, 41, 35-46.

Bowers, K. S., \& Farvolden, P. (1996). Revisiting a century-old Freudian slip-from suggestion disavowed to the truth repressed. Psychological Bulletin, 119, 355-380.

Cardena, E. (1994). The domain of dissociation. In S. J. Lynn \& J. W. Rhue (Eds.), Dissociation: Clinical and theoretical perspectives (pp. 15-31). New York: Guilford Press.

Carroll, J. S. (1978). The effect of imagining an event on expectations for the event: An interpretation in terms of the availability heuristic. Journal of Personality \& Social Psychology, 36, 1501-1511.

Clare, I. C. H., Gudjonsson, G. H., Rutter, S. C., \& Cross, P. (1994). The inter-rater reliability of the Gudjonsson Suggestibility Scale (Form 2). British Journal of Clinical Psychology, 33, 357-365.

DOBSON, M., \& MARKHAM, R. (1993). Imagery ability and source monitoring: Implications for eyewitness memory. British Journal of Psychology, 32, 111-118.

DrIsCOLL, L. N., \& WRIGHT, C. (1991). Survivors of childhood ritual abuse: Multi-generational satanic cult involvement. Treating Abuse Today, 1, 5-13.

Garry, M., Manning, C. G., Loftus, E. F., \& Sherman, S. J. (1996) Imagination inflation: Imagining a childhood event inflates confidence that it occurred. Psychonomic Bulletin \& Review, 3, 208-214.

GoFF, L. M., \& RoEDIGER, H. L., III (1998). Imagination inflation for action events: Repeated imaginings lead to illusory recollections. Memory \& Cognition, 26, 20-33.

Gregory, W. L., Cialdini, R. B., \& Carpenter, K. M. (1982). Selfrelevant scenarios as mediators of likelihood estimates and compliance: Does imagining make it so? Journal of Personality \& Social Psychology, 43, 89-99.

GuDJonsson, G. H. (1984). A new scale of interrogative suggestibility Personality \& Individual Differences, 5, 303-314.

Hilgard, E. R. (1965). Hypnotic susceptibility. New York: Harcourt, Brace \& World.

Hyman, I. E., JR., \& Billings, F. J. (in press). Individual differences and false childhood memories. Memory.

hyman, I. E., Jr., Gilstrap, L. L., Decker, K., \& Wilkinson, C. (1998). Manipulating remember and know judgments of autobiographical memories: An investigation of false memory creation. Manuscript submitted for publication. 
Hyman, I. E., JR., \& Pentland, J. (1996). The role of mental imagery in the creation of false childhood memories. Journal of Memory \& Language, 35, 101-117.

Johnson, M. K., Foley, M. A., Suengas, A. G., \& Raye, C. L. (1988). Phenomenal characteristics of memories for perceived and imagined autobiographical events. Journal of Experimental Psychology: General, 117, 371-376.

Johnson, M. K., Hashtroudi, S., \& Lindsay, D. S. (1993). Source monitoring. Psychological Bulletin, 114, 3-28.

Kassin, S. M. (1997). The psychology of confession evidence. American Psychologist, 52, 221-233.

Kinlstrom, J. F. (1987). The cognitive unconscious. Science, 237, 1445-1452.

LABelle, L., \& Perry, C. (1986, August). Pseudomemory creation in hypnosis. Paper presented at the 94 th Annual Convention of the American Psychological Association, Washington, DC

Laurence, J. R., \& Perry, C. (1983). Hypnotically created memory among highly hypnotizable subjects. Science, 222, 523-524.

LEAVITT, F. (1997). False attribution of suggestibility to explain recovered memory of childhood sexual abuse following extended amnesia. Child Abuse \& Neglect, 21, 265-272.

LofTus, E. F. (1997, September). Researchers are showing how suggestion and imagination can create "memories" of events that did not actually occur. Scientific American, 262, 71-75.

MaRKham, R., \& HyNES, L. (1992). The effect of vividness of visual imagery on reality monitoring. Journal of Mental Imagery, 17(3-4), 159-170.

MARKS, D. J. (1973). Visual imagery in the recall of pictures. British Journal of Psychology, 64, 17-24.
OFshE, R. J. (1992). Inadvertent hypnosis during interrogation: False confession due to dissociative state, misidentified multiple personality and the satanic cult hypothesis. International Journal of Clinical \& Experimental Hypnosis, 40, 125-156.

Register, P. A., \& Kinlstrom, J. F. (1988). Hypnosis and interrogative suggestibility. Personality \& Individual Differences, 9, 549-558.

Rossı, J. S. (1977). Reliability of a measure of visual imagery. Perceptuăl \& Motor Skills, 45, 694.

Sheehan, P. W., Statham, D., \& Jamieson, G. A. (1991). Pseudomemory effects and their relationship to level of susceptibility to hypnosis and state instruction. Journal of Personality \& Social Psychology, 60, 130-137.

SPIEGEL, D. (1995). Hypnosis and suggestion. In D. E. Schacter (Ed.), Memory distortion: How minds, brains, and societies reconstruct the past (pp. 129-149). Cambridge, MA: Harvard University Press

Tversky, A., \& Kahneman, D. (1973). Availability: A heuristic for judging frequency and probability. Cognitive Psychology, 5, 207-232.

WELLS, G. L., \& GAVANSKI, I. (1989). Mental simulation of causality. Journal of Personality \& Social Psychology, 56, 161-169.

Whalen, J. E., \& NASH, M. R. (1996). Hypnosis and dissociation: Theoretical, empirical, and clinical perspectives. In L. Michelson \& W. Ray (Eds.), Handbook of dissociation: Theoretical, empirical, and clinical perspectives (pp. 191-206). New York: Plenum.

Wright, D. B., \& LofTus, E. F. (in press). Measuring dissociation: Comparison of alternative forms of the Dissociative Experiences Scale. International Journal of Clinical \& Experimental Hypnosis.

(Manuscript received November 13, 1997; revision accepted for publication May 6, 1998.) 